\title{
Additional Conference Abstracts
}

\author{
The Evolutionary Basis for Variation in Access to Resources: Nonhuman Primate \\ Examples
}

Barbara B. Smuts

Department of Psychology, University of Michigan

This talk will provide an overview of how nonhuman primates acquire and use resources. It will focus on two aspects: sex differences in resource use, and variation across species in how females gain resources. These issues will be discussed within the framework of modern evolutionary theory, which emphasizes how access to resources affects individual reproductive success. In nonhuman primates, as in most animals, females and males use resources in very different ways. For females, the most important resource is usually food, because well-fed mothers produce more (and/or healthier) babies. For males, the most important "resource" is usually females, because males can reproduce only by exploiting female reproductive effort. These sex differences in use of resources lead to important sex differences in life histories, behavior, and social relationships. In addition to sex differences, nonhuman primates also show dramatic differences across species in the ways females gain access to resources. In some species female-female cooperation is critical to resource acquisition, while in others it is not. Specific examples and slides of nonhuman primates will be used to illustrate these general principles. The illustrative material will concentrate on baboons and chimpanzees, species studied by Barbara Smuts in East Africa.

Conservation and Development: Women's Participation in Decision-Making in Ankarana, Madagascar

\section{Lisa Gezon \\ Department of Anthropology}

Women in the village setting are active in making decisions about how resources of the material environment will be managed and used. Therefore, their participation in designing and implementing conservation and development projects is crucial to the success of those same projects. This paper will begin by analyzing the concept of "participation" in development literature and practice, examining the history of the method and how it has been used and misused. It will then suggest that effective participatory development entails the active involvement of women.

Women may have formal political decision-making roles in a given commu-

Population and Environment: A Journal of Interdisciplinary Studies

Volume 18, Number 2, November 1996

(C) 1996 Human Sciences Press, Inc. 
POPULATION AND ENVIRONMENT

nity, but often their most important contribution lies in their informal influence in political processes. Research in the Ankarana region of northwest Madagascar provides several cases of women's formal and informal involvement in processes of dispute over the allocation of resources. Conservation projects in Madagascar and elsewhere can be more effective in encouraging non-destructive use of the environment when women's positions in land management and village-level decision-making are acknowledged.

\section{Women and Soil Conservation: Sub-Saharan Africa}

Jacquelyn Miller

School of Natural Resources and Environment, University of Michigan

An important basis for sustainable development is soil conservation, which is central to issues of land degradation, food production, desertification, water quality, fuelwood supply, and poverty. Yet the insidious and gradual nature of soil erosion and declining fertility often leads to the bypass of soil management in favor of more immediate concerns. For women in sub-Saharan Africa, additional constraints of insecure tenure, labor demands, poverty, and gender bias in extension and training inhibit their investment in soil conservation measures. Despite these barriers, women in many societies engage in a variety of soil conservation management activities at both individual and group levels, with impressive leadership, organization, and successes.

The shortage of case studies exploring women's roles in soil conservation in environmental literature indicates the necessity of a more concrete, historical, and contextualized approach to women in sustainable development. The history of the women's uprising in Kenya, for example, illustrates the potential backlash of women against compulsory soil conservation labor. As both population growth and soil erosion tend to have higher prioritization on national and international agendas than on the agendas of African women, a parallel can be drawn between coercive soil conservation policies and coercive population policies with narrow demographic aims. A more holistic reproductive health and empowerment approach would focus on removing the barriers which hinder women's conservation activities and fertility choices, rather than further infringing upon their authority. Finally, the absence of women's issues in literature on soil conservation implies the need for gender-disaggregated data and project approaches.

Women and Sustainable Development: A Case Study of the Green Belt Movement of Kenya

Njoki Njoroge Njehu

Greenpeace International Toxic Trade Campaign, Green Belt Movement, Kenya

In many developing countries, development has adversely affected the natural resource base through deforestation, soil erosion, water pollution, over-stocking and 
cash crop farming, among others. Women, and in particular, rural women who are very dependent on this decimated environment, have had to develop coping mechanisms to address the environmental problems which threaten the base of their food production and the food security of their families. In addition, colonial and postcolonial policies have altered the interaction of women and their environment, and hampered women's subsistence and survival. The attempted interventions and improvements have tended to further burden women due to heavy reliance on their labor and participation, whether coerced or voluntary. In Kenya, women provide up to 80 percent of the labor in development projects. The Green Belt Movement provides a case study of a project which has tried to address some of the problems associated with traditional development programs, while focusing on the status of women and protection of the environment.

Like much of the global South, Kenyan women interact with and closely depend on their natural environment (water, soils, forests, wildlife, etc.) in everyday activities and in meeting basic needs. Among their many tasks, women are the gatherers of fuelwood and the providers of food, with primary responsiblity for growing, storing and preparing food for their families. Women are also the health care providers and, in the absence of adequate or reliable modern medical facilities, they often rely on the environment for medicines. And finally, women must bear the primary burden of raising children. Continent-wide, African women head 40 percent of households, while in parts of rural Kenya, women head 60 percent of households.

In food production for themselves and their families, women in Kenya constantly face and manage environmental and food crises. Due to this high reliance on the natural environment, women are often the first casualties of environmental degradation and crises. However, as noted by the Commonwealth Secretariat (1991), women are not merely the victims of environmental degradation; as food producers and managers of natural resources, women play a vital role in environmental conservation.

The Green Belt Movement of Kenya, founded in 1977 as a tree-planting project of the National Council of Women of Kenya, is one example of a conservation and sustainable development effort. Its long and short-term goals include: to encourage tree planting; to raise public awareness on the connections between environmental status and issues such as poverty, mismanagement of resources, fuelwood and food scarcity and unemployment; to promote environmental conservation and sustainable development; to promote a positive image of women and their roles in nationsl development; and to promote the protection and maintenance of the environment.

\section{The Importance of Gender Analysis: The Pwo Karen of Thailand}

\section{Sara Peracca}

School of Natural Resources, School of Public Health, Department of Sociology, University of Michigan,

The current development model recognizes the importance of local participation in the development process. Within this framework, there is an emphasis on the need to specifically involve women. However, women's representation is often 
not achieved. This lack of integration of women is largely due to the adherence of many development agencies, organizations and donors to the basic assumption that women are subordinate to men in all societies. This view overlooks not only the complexities of women's situations within various cultures but also that in some cultures the roles of women and men are equally respected.

The integrity of a participatory project can be compromised when inequities real or supposed are remedied by including women only in peripheral activities. To ensure against the marginalization of women, it is argued that a gender analysis should be conducted at various stages throughout a project. By conducting a gender analysis, project implementors will be forced to recognize the intricacies of gender relations within another culture even if they do not ascribe to a basic ideology of gender equality. The study of roles, resources, and responsibilities associated with each gender, allows for the evaluation of the project's impacts on the community as well as the impacts on the project's goals.

A case study of a conservation project involving an indigenous group, the Karen in western Thailand, serves to illustrate this point. The project aims to enable the Karen to remain living within a protected area. Although the Karen culture appears to value the roles of women and men equally and the project enlisted many participatory methods, the women have been only peripherally involved in the project. Consequently, the project may be negatively affecting both the gender balance in this community and ultimately the goal of the project.

\section{From Theory to Practice: A Mexican Case Study of Population and Environment}

\section{Amy Weissman}

School of Natural Resources \& Environment, School of Public Health

There has been a recent resurgence of the theoretical debate concerning the association between population dynamics and environmental degradation. Although the development community has great interest in integrating the population and environmental fields, the most effective means to accomplish this task remains unclear. A case study in central Mexico is examined to determine how the development community might shift from a theoretical perspective to a practical application of integrated projects. In the state of Guanajuato a non-governmental organization providing family planning and health care services has recently begun to incorporate environmental planning into its programs. Samuel Paul's framework for strategic management is used to analyze this process and determine the organization's readiness and ability to deliver an effective integrated program. From this case study, conclusions are drawn concerning the problems and successes specific to the organization as well as those that are intrinsic to the process of integration. 